\title{
Tecnologias avançadas de tratamento visando à remoção de cor e fenol de efluente de indústria de celulose e papel
}

\author{
Advanced treatment technologies for the removal of color and phenol from the \\ effluent of paper industry wastewater
}

Ana Flávia Bender ${ }^{I}$, Jeanette Beber de Souza ${ }^{I I}$, Carlos Magno de Sousa Vidal'II

\begin{abstract}
Resumo
O presente artigo teve como enfoque a remoção de cor e fenol presentes em efluente proveniente da indústria de papel e celulose a partir do emprego das tecnologias avançadas: (i) coagulação/floculação/ sedimentação, (ii) filtração em carvão ativado, (iii) combinação de coagulação/floculação/sedimentação com a filtração em carvão ativado. Os ensaios foram realizados em jarteste e unidade de filtração em escala de bancada. Os principais resultados obtidos foram remoções de: $89 \%$ da cor e $60 \%$ do fenol no tratamento por coagulação, floculação e sedimentação; $45 \%$ da cor e $47 \%$ do fenol no tratamento por filtração em carvão ativado e $99 \%$ da cor e acima de $93 \%$ de fenol ao tratar o efluente por ciclo completo (coagulação, floculação, sedimentação seguido de filtração). Com esse último tratamento foi possível obter efluente final com elevada qualidade e atender à legislação ambiental sob diversos aspectos.
\end{abstract}

Palavras-chave: Efluentes industriais; Tratamento terciário; Carvão ativado

\begin{abstract}
This paper analyzes the removal of colour and phenol found in pulp and paper industry wastewater using advanced technologies: (i) coagulation-flocculation-sedimentation, (ii) granular activated carbon filtration, (iii) combination of coagulation-flocculation-sedimentation and granular activated carbon filtration. Jar tests and bench-scale column tests were performed. The main results obtained were: removals of $89 \%$ and $60 \%$ for colour and phenol, respectively, using coagulation-flocculation-sedimentation; for activated carbon filtration, overall colour and phenol removal of $45 \%$ and $47 \%$, respectively; and maximum removals obtained were $99 \%$ for colour and above $93 \%$ for phenol, when the complete cycle (coagulation-flocculationsedimentation combined with filtration) was tested. Along with this last treatment, it was possible to obtain a high quality final effluent and to comply with the environmental regulations in several aspects.
\end{abstract}

Keywords: Industrial effluents; Tertiary treatment; Activated carbon

Engenheira Ambiental, MSc., Universidade Estadual do Centro-Oeste, Campus Irati, Riozinho, s/n, CEP 84500-000, Irati (PR), Brasil. anafbender@ hotmail.com (ORCID:0000-0003-1015-5754)

Engenheira Civil, Dra., Professora Associada da Universidade Estadual do Centro-Oeste, Campus Irati, Riozinho, s/n, CEP 84500-000, Irati (PR), Brasil. jeanettebeber@yahoo.com.br (ORCID:0000-0002-5375-512X)

III Biólogo, Dr., Professor Associado da Universidade Estadual do Centro-Oeste, Campus Irati, Riozinho, s/n, CEP 84500-000, Irati (PR), Brasil. cacavidal@yahoo.com.br (ORCID:0000-0002-5839-5610) 


\section{Introdução}

Quando o assunto é poluição industrial, o setor de celulose e papel atua como um personagem importante, tendo em vista a gama variada de poluentes encontrados nas emissões, bem como a quantidade significativa de água requerida nas diferentes etapas do processo produtivo, que oscila entre 15 a $100 \mathrm{~m}^{3} / \mathrm{t}$, dependendo do tipo de unidade industrial. A água é utilizada em várias etapas do processo fabril: descascamento e lavagem das toras no pátio de madeiras, dispersão da celulose, lavagem de polpa, produção de vapor, preparação de aditivos, entre outros. Isso traz como consequência outro aspecto ambiental importante que é a geração de consideráveis volumes de efluentes ao final do sistema, também com elevado potencial de poluição, contendo, entre outros: substâncias orgânicas originárias da própria madeira (celulose, hemicelulose, lignina); nitrogênio e fósforo, advindos do esgoto sanitário da empresa pelos refeitórios e sanitários; sólidos suspensos (cascas, fibras, areia, etc.); metais pesados, oriundos do processo de produção do papel; compostos organoclorados; ácidos, além dos compostos fenólicos e os que geram cor (THOMPSON et al., 2001; LACORTE et al., 2003; COMPANHIA DE TECNOLOGIA DE SANEAMENTO AMBIENTAL, 2008).

Derivados fenólicos são compostos que não ocorrem naturalmente em corpos d'água, sendo sua presença no ambiente associada necessariamente à atividade humana. Estes grupos são encontrados em rejeitos de diferentes tipos de indústrias, tais como: farmacêutica, mineradora, petroquímica, papel e celulose, têxtil, entre outras (CUNHA; AGUIAR, 2014). Os fenóis são reconhecidos como poluentes prioritários pela Agência de Proteção Ambiental (EPA) dos Estados Unidos e pela União Europeia (EU), devido à sua toxicidade aguda e elevada solubilidade (MING et al., 2006 apud MONTIBELLER, 2012).

Os compostos que geram cor presente nos efluentes das indústrias de papel e celulose têm como origem a lignina e seus derivados, que, além da coloração propicia a difícil degradação biológica do efluente (CLETO; GUIMARÃES; BUZZINI, 2007). Embora a cor não esteja necessariamente relacionada a problemas de contaminação dos corpos hídricos, ela causa problemas de ordem estética e dificuldades na penetração da luz, além de poder estar relacionada a compostos recalcitrantes que, nesse caso, sim, em geral, são tóxicos à comunidade aquática (PIVELI; KATO, 2005).

Em contrapartida aos impactos e aspectos ambientais negativos associados, o setor de celulose e papel brasileiro está há anos entre os principais setores produtivos do mundo, trazendo significativa contribuição para a balança comercial e gerando muitos empregos e renda em todas as regiões do país. Em 2016 estimou-se que, no total, o número de postos de trabalhos da atividade de base florestal - diretos, indiretos e resultantes do efeito renda - tenha sido de aproximadamente 3,7 milhões. Nos anos de 2016 e 2017, o setor brasileiro apresentou crescimento expressivo, apesar da predominante crise econômica instalada no país. Em 2017, o setor brasileiro de árvores plantadas foi responsável por 6,2\% do PIB industrial do País e foi um ano de avanço generalizado nas negociações com o mercado externo em todos os segmentos das indústrias de base florestal, o que contribuiu para o desempenho positivo desse setor, em grande monta, segundo especialistas da Indústria Brasileira de Árvores (IBÁ) foi a aposta em inovação (INDÚSTRIA BRASILEIRA DE ÁRVORES, 2017).

Assim, trazer inovação para essa área, que gere economia de recursos e maior sustentabilidade, como é o caso da temática abordada nessa pesquisa, é a chave para continuar propiciando maior produtividade e competitividade ao setor.

Atualmente, as tecnologias de tratamento de efluentes usualmente adotadas por essas indústrias são baseadas em processos físicos seguidos de mecanismos biológicos, que, via de regra, mostram-se insuficientes na obtenção de efluentes isentos de compostos recalcitrantes, ou compostos mais resistentes à degradação biológica como é o caso do fenol e remoção de compostos dissolvidos e coloidais como os que são res ponsáveis pela cor. Nesses casos, tecnologias de tratamento avançado constituem-se alternativas para obtenção de efluentes tratados com 
qualidade superior, os quais tornam-se passíveis de enquadramento aos padrões de emissão em conformidade com a legislação ambiental ou tornam-se aptos ao reuso, podendo propiciar o chamado "fechamento de circuitos" em uma unidade fabril (POKHREL; VIRAGHAVAN, 2004 apud BONFIM et al., 2012; FOLLMANN, 2017).

Dentre as tecnologias de tratamento avançado propostas como alternativas para esses efluentes industriais destacam-se a coagulação/floculação/sedimentação, eletrocoagulação, flotação por ar dissolvido, processos oxidativos avançados, processos de adsorção em carvão ativado e processos de separação por membranas (MANCUSO; SANTOS, 2003). A escolha de uma ou a combinação entre duas ou mais técnicas de tratamento dependerá do potencial de cada tecnologia envolvida na redução do contaminante de interesse e da qualidade da água que se deseja obter (MIERZWA; HESPANHOL, 2005).

Em relação à cor e turbidez das águas residuárias, os métodos mais utilizados para removê-los são à base de coagulação, floculação e sedimentação (PIVELI; KATO, 2005).

Apesar de serem etapas distintas, a coagulação, floculação e sedimentação são interdependentes. A coagulação tem como principal objetivo neutralizar as cargas elétricas das partículas em suspensão, por meio da adição de compostos químicos com cargas positivas, proporcionando a posterior formação de flocos densos em condições de sedimentar (em decantadores ou flotadores). Já a floculação é o processo pelo qual as partículas, em estado de equilíbrio eletrostaticamente instável na massa líquida, são forçadas a se movimentarem para que sejam atraídas entre si formando flocos mais pesados e resistentes, os quais poderão ser extraídos com mais facilidade posteriormente. Por fim, a sedimentação é um fenômeno físico em que, devido à força da gravidade, as partículas suspensas apresentam movimento descendente em meio líquido de menor massa específica. A ocorrência desses fenômenos acarreta na clarificação, a partir da separação da fase sólida da líquida (DI BERNARDO; DANTAS, 2005; LIBÂNIO, 2010).

Em relação à concentração de fenóis presentes em efluentes industriais, esta pode ser reduzida por processos físico-químicos à base de oxidação química, mas que, em geral, apresentam eficiências variáveis, dependendo das características de cada efluente, podendo não garantir o atendimento à legislação ambiental que trata do lançamento desses efluentes. Dentre os processos de tratamento para a remoção de compostos fenólicos, a adsorção em carvão ativado é a alternativa que produz a melhor eficiência em uma maior faixa de aplicabilidade (PIVELI; KATO, 2005; MONTIBELLER, 2012). O material adsorvente mais utilizado é o carvão ativado, por sua disponibilidade e custo, sendo eficiente na remoção de compostos orgânicos voláteis, tais como hidrocarbonetos, solventes, gases tóxicos e odores (METCALF; EDDY, 2016).

A adsorção é uma operação de transferência de massa, uma vez que um constituinte (adsorvato/adsorbato) é transferido da fase fluida (gás, vapor ou líquido) para uma fase sólida (adsorvente). O adsorvente é o material sólido em cuja superfície, interna e/ou externa, ocorre o fenômeno de adsorção e o adsorbato a substância retida pelo adsorvente (VACLAVIK, 2010). No tratamento de efluentes, a adsorção é considerada uma etapa de polimento final, utilizada quando há necessidade de tratamento com qualidade mais elevada, após tratamento biológico ou tratamento físico-químico à base de coagulação/floculação/sedimentação e filtração (SILVA FILHO, 2009).

Os carvões ativados são materiais com alto teor de carbono e que sofreram processamento para aumento da porosidade interna. Uma vez ativado, o carvão passa a apresentar elevada superfície interna (500 a $1200 \mathrm{~m}^{2} / \mathrm{g}$ ) localizada dentro da rede de poros, na qual, a maior parte do processo de adsorção acontece. Esse material é capaz de adsorver as moléculas sem modificar a composição química do produto adsorvido (DI BERNARDO; DANTAS, 2005).

O carvão ativado granular $(C A G)$ é produzido a partir de matérias-primas duras e processo controlado, resultando em um produto de estrutura rígida (o que evita perdas excessivas devido à fricção). A alta dureza permite regenerações sucessivas, tornando os processos que são operados em leitos mais econômicos. Essa forma de carvão é utilizada em filtros de pressão ou por gravidade, através dos quais o fluido passa e é purificado (MANCUSO; SANTOS, 2003). 
O presente artigo teve como objetivo avaliar se o desempenho da coagulação/floculação/ sedimentação e da adsorção em carvão ativado granular no tratamento avançado de efluente de uma indústria de papel e celulose é eficaz, e quão eficaz é, para remoção de cor elevada e fenol de uma matriz real e altamente complexa como é o caso de efluente proveniente do processo Kraft.

\section{Materiais e métodos}

\section{Caracterização do efluente}

O efluente utilizado na pesquisa foi disponibilizado por uma indústria de papel e celulose brasileira, a qual emprega o processo kraft na produção de pasta. A estação de tratamento de efluente (ETE) dessa indústria era composta pelas seguintes unidades em sequência: calha parshall, grade, decantador primário, tanque de aeração e decantador secundário.

A coleta do efluente foi realizada na saída do decantador secundário, após o tratamento biológico, denominado efluente bruto, ou seja, aquele que passará pela sequência de tratamentos avançados aqui propostos. A coleta e preservação das amostras de efluente foram realizadas de acordo com os procedimentos descritos na norma ABNT NBR 9898 (1987).

As análises físico-químicas de caracterização do efluente bruto e das amostras tratadas foram realizadas de acordo com as determinações preconizadas no Standard Methods for the Examination of Water and Wastewater (AMERICAN PUBLIC HEALTH ASSOCIATION; AMERICAN WATER WORKS ASSOCIATION; WATER ENVIRONMENT FEDERATION, 2012), especificadas na Tabela 1.

\section{Tabela 1 - Parâmetros analisados, métodos analíticos e equipamentos empregados na pesquisa.}

Table 1 - Parameters analyzed, analytical methods and research equipment.

\begin{tabular}{|c|c|c|}
\hline Parâmetro & $\begin{array}{l}\text { Método analítico e equipamento } \\
\text { utilizado }\end{array}$ & $\begin{array}{c}\text { Número do método, segundo } \\
\text { American Public Health } \\
\text { Association; American Water } \\
\text { Works Association; Water } \\
\text { Environment Federation } \\
(2012)\end{array}$ \\
\hline Turbidez (uT) & Nefelométrico - Turbidímetro 2100 Q, Hach & $2130 \mathrm{~B}$ \\
\hline Cor verdadeira (uC) & $\begin{array}{l}\text { Espectrofotometria - Espectrofotômetro UV- } \\
\text { Vis DR } 6000 \text {, Hach }\end{array}$ & $2120 \mathrm{C}$ \\
\hline DQO solúvel (mg L'-1) & $\begin{array}{l}\text { Colorimétrico - Espectrofotômetro UV-Vis DR } \\
6000, \text { Hach }\end{array}$ & $5220 \mathrm{D}$ \\
\hline $\mathbf{p H}(-)$ & $\begin{array}{c}\text { Potenciométrico - peagâmetro PHS-3B, } \\
\text { PHTEK }\end{array}$ & $4500-\mathrm{H}^{+} \mathrm{B}$ \\
\hline Fenol $\left(\mathbf{m g ~ L}^{-1}\right)$ & $\begin{array}{l}\text { Colorimétrico - Espectrofotômetro UV-Vis DR } \\
6600, \text { Hach }\end{array}$ & $5530 \mathrm{~B}$ \\
\hline
\end{tabular}

Fonte: Autores (2018) 
Além dos parâmetros descritos anteriormente, realizou-se a análise do perfil espectrofotométrico, na região compreendida entre 200 e $800 \mathrm{~nm}$, a fim de monitorar as mudanças na área espectral. Essa análise foi realizada com o emprego do espectrofotômetro UV-Vis DR 6000, Hach, empregando cubeta de quartzo com $1 \mathrm{~cm}$ de caminho ótico.

\section{Equipamentos utilizados nos ensaios de tratabilidade}

\section{Unidade de coagulação/floculação/sedimentação}

Os ensaios de coagulação/floculação/sedimentação foram realizados em equipamento de reatores estáticos do tipo jarteste composto por seis jarros de acrílico com capacidade volumétrica de dois litros cada, da marca Policontrol, modelo FlocControl III. Os ensaios em jarteste permitem simular as condições operacionais, por meio de variações de dosagens, gradientes de velocidade de mistura, tempos de mistura e tempos de sedimentação.

$\mathrm{Na}$ presente pesquisa utilizou-se como agente coagulante o tanino Acquapol S5T, de caráter catiônico, líquido com coloração castanho-escura, densidade de 1,07 a 1,17 g.cm ${ }^{-3}$ e pH médio de 2,3 .

\section{Unidade de filtração}

Os ensaios de filtração foram realizados em filtros de laboratório preenchidos com carvão ativado granular (FLCAGs), a partir de um kit composto por seis filtros de acrílico preenchidos com $15 \mathrm{~cm}$ de CAG e suporte para acoplamento no jarteste.

O CAG utilizado possuía as seguintes características de acordo com Baettker (2015): pH = 6,7 ; massa especifica aparente $=0,63 \mathrm{~g} \mathrm{~cm}^{-3}$; densidade $=1,27 \mathrm{~g} \mathrm{~cm}^{-3}$; módulo de finura $=2,98$; teor de material volátil $=51 \%$; teor de cinzas $=5,89 \%$; número de iodo $=665,86 \mathrm{mg} \mathrm{g}^{-1}$; e porosidade $=$ $86 \%$.

\section{Ensaios de tratabilidade}

Os ensaios de tratabilidade (coagulação/floculação/sedimentação e filtração em carvão ativado granular) foram realizados de acordo a metodologia proposta por Di Bernardo, Dantas e Voltan (2011) para "ensaios de tratabilidade em ciclo completo".

Visando avaliar o desempenho dos tratamentos na remoção dos constituintes cor e fenol, realizaram-se as três séries de ensaios, descritas como séries I, II e III, cujos parâmetros otimizados são apresentados a seguir.

Série I: Ensaios de coagulação/floculação/sedimentação

- Dosagem de coagulante (tanino): $250 \mathrm{mg} \mathrm{L}^{-1}$;

- Homogeneização da amostra: tempo de $10 \mathrm{~s}$ com gradiente de velocidade de $100 \mathrm{~s}^{-1}$;

- Mistura rápida: tempo de $30 \mathrm{~s}$ com gradiente de velocidade de $500 \mathrm{~s}^{-1}$;

- Mistura lenta: tempo de 10 min com gradiente de velocidade de $40 \mathrm{~s}^{-1}$;

- Tempo de sedimentação de 20 min.

Série II: Ensaio de filtração adsortiva em CAG

- Vazão de filtração: entre 14 e 16 L.min ${ }^{-1}$ (correspondente à taxa média de 71 e $81 \mathrm{~m}^{3} \cdot \mathrm{m}^{-2}$. $\mathrm{dia}^{-1}$, respectivamente) 
- Tempo de filtração: 20 minutos, quando então se realizou a coleta do filtrado.

\section{Série III: Ensaios em ciclo completo}

O ensaio em ciclo completo é caracterizado pelo ensaio de coagulação/floculação/ sedimentação seguido da filtração da amostra clarificada em coluna de CAG. Nessa série de ensaios repetiram-se as configurações adotadas na Série I e, em seguida, realizada a filtração direta descendente do efluente decantado nas mesmas configurações da Série II.

As leituras dos valores residuais referentes aos parâmetros estudados foram realizadas ao final da sedimentação, com amostras do efluente decantado, e ao final da filtração, tanto para a filtração do efluente clarificado quanto para o bruto (sem passar pela clarificação), sendo avaliados os parâmetros: cor verdadeira, turbidez, DQO solúvel, fenol, pH. Também foi feita a varredura espectrofotométrica a partir das amostras brutas e tratadas.

\section{Análise estatística}

A análise estatística foi feita no software livre e gratuito $\mathrm{R}$ versão 3.4.2. Os dados foram previamente checados quanto à gaussianidade dos resíduos e homogeneidade das variâncias pelo teste de Shapiro-Wilk e Bartlett, respectivamente, ao nível de significância de 5\%. Foram utilizadas três repetições por tratamento.

Para avaliar o desempenho dos processos de coagulação/floculação/sedimentação e de adsorção em carvão ativado granular, efetuou-se teste t de Student para amostras independentes para os parâmetros: cor verdadeira, turbidez, DQO solúvel e fenol.

\section{Resultados e discussão}

Na Tabela 2 são apresentados os resultados da caracterização físico-química do efluente.

\section{Tabela 2 - Caracterização do efluente final da ETE da indústria de papel e celulose.}

Table 2 - Characterization of final effluent of ETE from pulp and paper industry.

\begin{tabular}{lc}
\hline Parâmetro & Médias de valores e desvio padrão \\
\hline Cor Verdadeira $(\mathbf{u C})$ & $707,0 \pm 106,0$ \\
Turbidez $(\mathbf{u T})$ & $7,4 \pm 0,6$ \\
DQO Solúvel $\left(\mathbf{m g ~ L}^{-1}\right)$ & $141,0 \pm 2,0$ \\
Fenol $\left(\mathbf{m g}^{-1} \mathbf{L}^{-1}\right)$ & $7,8 \pm 0,7$ \\
pH & $8,3 \pm 0,0$ \\
\hline
\end{tabular}

Fonte: Autores (2018)

Conforme observado na Tabela 2, a caracterização do efluente demonstrou a existência de matéria orgânica remanescente (avaliada pelo parâmetro DQO) mesmo após passar pelo tratamento biológico, constatando-se a real dificuldade para tratar efluentes desse ramo industrial.

O valor de fenol apresentou-se elevado. De acordo com a Resolução CONAMA n 430/2011 que "dispõe sobre as condições e padrões de lançamento de efluentes" (BRASIL, 2011), o valor máximo permitido (VMP) de lançamento para fenóis totais é de $0,5 \mathrm{mg} . \mathrm{L}^{-1}$, sendo que os valores detectados na caracterização do efluente final da indústria estudada foram bem acima do que permite a legislação ambiental em vigor. 
Também, os valores de cor do efluente estavam elevados. Nas indústrias de celulose e papel, a coloração elevada é devida à presença de lignina e celulose presentes de forma abundante nesse tipo de efluente. A não inclusão da cor como padrão de emissão de efluentes faz com que algumas indústrias contem com as diluições que os efluentes passarão no próprio receptor e não realizem o tratamento específico para sua remoção residual. Entretanto, apesar da cor não ser regulamentada e não significar, necessariamente, problemas de contaminação nas águas naturais, a cor, além de dificultar a penetração da luz (redução da zona eufótica), pode estar associada à presença de compostos recalcitrantes que, em geral, são tóxicos aos organismos aquáticos. Sendo assim, é importante alcançarem-se valores de cor residual inferiores aos observados na Tabela 2.

Observou-se nesse estudo que, os efluentes desse ramo industrial mesmo após o sistema secundário de tratamento (biológico), ainda necessitavam de tratamento adicional.

De acordo com Metcalf e Eddy (2016), os contaminantes típicos encontrados, como a presença de material particulado, ou coloidal, orgânico e inorgânico, apresentam significados ambientais expressivos como por exemplo: causam depósitos de lodos ou comprometem a transparência da água do corpo receptor, afetam a turbidez do efluente, reduzem a concentração de oxigênio dissolvido no corpo receptor, também os compostos orgânicos dissolvidos, além da redução da concentração de OD no corpo receptor, podem provocar toxicidade química para organismos vivos, contribuir na formação de oxidantes fotoquímicos e agentes carcinogênicos, induzirem efeitos nas espécies aquáticas (alterações endócrinas), propiciar a formação de espuma e interferir na coagulação.

\section{Série I - Ensaios de coagulação/floculação/sedimentação}

Na Tabela 3 é apresentado o resumo do teste t de Student para os parâmetros estudados, a caracterização físico-química do efluente bruto, da amostra tratada por coagulação/floculação/ sedimentação, bem como as respectivas porcentagens de remoção para cada um dos parâmetros avaliados.

\section{Tabela 3 - Resumo do teste t de Student para os parâmetros analisados no processo de coagulação/floculação/sedimentação com amostra bruta.}

Table 3 - Summary results of paired t-tests on parameters analyzed in raw wastewater and after the coagulation-flocculation-sedimentation process.

\begin{tabular}{lccccc}
\hline \multicolumn{1}{c}{ Parâmetro } & Amostra Bruta & Amostra Tratada & $\mathbf{R}(\%)$ & $\mathbf{t}$ & $\mathbf{p}$ \\
\hline Cor Verdadeira $(\mathbf{u C})$ & 707,0 & 77,0 & 89 & 9,91 & $0,0050^{*}$ \\
Turbidez $(\mathbf{u T})$ & 7,4 & 2,8 & 62 & 38,55 & $0,0003^{*}$ \\
DQO Solúvel $\left(\mathbf{m g ~ L}^{-1}\right)$ & 141,0 & 119,0 & 16 & 6,24 & $0,0123^{*}$ \\
Fenol $\left(\mathbf{m g ~ L}^{-1}\right)$ & 7,8 & 3,1 & 60 & 32,11 & $0,0004^{*}$ \\
\hline
\end{tabular}

Em que: $\mathrm{R}=$ Remoção; $\mathrm{t}$ = valor de $\mathrm{t}$ calculado pelo teste; ${ }^{*}=$ significativo a $5 \%$ de probabilidade de erro, pelo teste $t$ de Student.

A partir dos dados apresentados na Tabela 3 observou-se que para todos os parâmetros foram obtidas reduções percentuais significativas $(\mathrm{p}<0,05)$ pelo teste de $t$ de Student, demostrando que o tratamento por coagulação/floculação/sedimentação foi efetivo.

Observou-se que para o parâmetro cor verdadeira alcançou-se percentual de redução de $89 \%$, enquanto que, para os parâmetros turbidez e fenol, as reduções foram de 62 e $60 \%$, respectivamente. Em contrapartida, a redução de DQO foi de $16 \%$. 
Kuritza (2012) ao avaliar o emprego do conjunto coagulação/floculação/sedimentação no pós-tratamento do efluente de uma indústria de papel e celulose, utilizando como agente coagulante o policloreto de alumínio (PAC) pode verificar que: com a dosagem de $250 \mathrm{mg}$. $\mathrm{L}^{-1}$ foi possível atingir redução de $85 \%$ da cor e turbidez do efluente. Com isso pode-se fazer um comparativo com o presente trabalho, no qual a aplicação de $250 \mathrm{mg} . \mathrm{L}^{-1}$ do coagulante tanino resultou em redução de $89 \%$ da cor. Em relação à turbidez, os resultados foram inferiores neste estudo, no entanto, vale ressaltar que no trabalho de Kuritza, o valor bruto de turbidez era muito maior $(611 \mathrm{uT})$ o que explica a maior porcentagem de remoção deste parâmetro.

Segundo Piveli e Kato (2005), há dificuldades no tratamento de águas quando estas apresentam cor elevada e turbidez baixa, o que foi observado nesse estudo (Tabela 2), nesses casos há falta de partículas maiores que possibilitem a ocorrência de nucleação, tornando os flocos pequenos e de baixa velocidade de sedimentação, dificultando o processo. Dessa forma, a turbidez baixa desse efluente interferiu na remoção de alguns parâmetros.

Ainda comparando-se este trabalho com o de Kuritza (2012) observa-se a mesma dificuldade na remoção da DQO. A autora ao utilizar o agente coagulante policloreto de alumínio (250 mg. $\mathrm{L}^{-1}$ ) obteve redução de $38,7 \%$ da DQO. Neste caso, para que o tratamento fosse mais efetivo aplicou-se polímero aniônico como auxiliar de coagulação $\left(1 \mathrm{mg} \mathrm{L}^{-1}\right)$ alcançando-se então 75\% de eficiência de remoção de DQO.

\section{Série II: Ensaio de filtração em CAG}

Na Tabela 4 é apresentado o resumo do teste t de Student para os parâmetros estudados, a caracterização físico-química do efluente bruto e da amostra tratada por filtração em carvão ativado granular, bem como a respectiva porcentagem de remoção para cada um dos parâmetros avaliados.

\section{Tabela 4 - Resumo do teste t de Student para os parâmetros analisados no processo de filtração em CAG com amostra bruta.}

Table 4 - Summary results of paired t-tests on parameters analyzed in raw wastewater and after treatment by GAC filtration.

\begin{tabular}{lccccc}
\hline \multicolumn{1}{c}{ Parâmetro } & Amostra Bruta & Amostra Tratada & R $(\%)$ & t & p \\
\hline Cor Verdadeira (uC) & 707,0 & 388,0 & 45 & 5,467 & $0,0159^{*}$ \\
Turbidez (uT) & 7,4 & 2,8 & 62 & 13,314 & $0,0027^{*}$ \\
DQO Solúvel $\left(\mathbf{m g . L}^{-1}\right)$ & 141,0 & 87,6 & 38 & 12,246 & $0,0033^{*}$ \\
Fenol $\left(\mathbf{m g . L}^{-1}\right)$ & 7,8 & 4,2 & 47 & 10,392 & $0,0045^{*}$ \\
\hline
\end{tabular}

Em que: $\mathrm{R}=$ Remoção; $\mathrm{t}$ = valor de $\mathrm{t}$ calculado pelo teste; ${ }^{*}=$ significativo a $5 \%$ de probabilidade de erro, pelo teste t.

Conforme Tabela 4, observou-se que para todos os parâmetros foram obtidas remoções significativas $(\mathrm{p}<0,05)$ pelo teste de $t$ de Student, demostrando que o tratamento por filtração do efluente bruto em carvão ativado granular foi efetivo para todos os parâmetros estudados.

Entretanto, nessa etapa do estudo, as reduções percentuais nos valores dos parâmetros estudados foram intermediárias, tendo em vista que, o maior percentual de redução obtido foi de $62 \%$ para o parâmetro turbidez, enquanto que as demais reduções foram inferiores a $50 \%$. 
Além disso, os resultados apresentados na Tabela 4 deixam claro que o tratamento por filtração em CAG com o efluente bruto foi inferior quando comparado aos resultados obtidos com a amostra tratada por meio de coagulação/floculação/sedimentação (Tabela 3).

De acordo com Metcalf e Eddy (2016), a aplicação do processo de adsorção no tratamento de efluentes nunca envolve um único contaminante, mas uma mistura complexa, considerada como adsorção de múltiplos contaminantes. Geralmente, as características do efluente a ser tratado resultam em uma redução significativa da capacidade de adsorção de um contaminante específico na presença de muitos outros, embora a capacidade total de adsorção possa ser muito maior. A inibição da adsorção devido à competição entre os compostos presentes está relacionada ao tamanho das moléculas que estão sendo adsorvidas, à sua afinidade com o adsorvente e à sua concentração relativa.

Individualmente, nenhum dos dois tratamentos realizados nas séries I e II possibilitou a redução de fenóis a valores menores que $0,5 \mathrm{mg} \mathrm{L}^{-1}$ conforme exigência da legislação ambiental, demostrando a necessidade de um tratamento mais avançado.

\section{Série III: Ensaios em ciclo completo}

Na Tabela 5 é apresentado o resumo do teste t de Student para os parâmetros estudados, a caracterização físico-química do efluente bruto, da amostra tratada em ciclo completo, bem como a respectiva porcentagem de remoção para cada parâmetro avaliado.

\section{Tabela 5 - Resumo do teste t de Student para os parâmetros analisados no processo por ciclo completo.}

Table 5 - Summary results of paired t-tests on parameters analyzed in raw wastewater and after treatment by complete cycle.

\begin{tabular}{lccccc}
\hline \multicolumn{1}{c}{ Parâmetro } & Amostra Bruta & Amostra Tratada & R (\%) & t & p \\
\hline Cor Verdadeira $(\mathbf{u C})$ & 707,0 & 6,0 & 99 & 11,08 & $0,0040^{*}$ \\
Turbidez $(\mathbf{u T})$ & 7,4 & 0,7 & 91 & 16,68 & $0,0017^{*}$ \\
DQO Solúvel $\left(\mathbf{m g ~ L}^{-1}\right)$ & 141,0 & 51,4 & 64 & 18,76 & $0,0028^{*}$ \\
Fenol $\left(\mathbf{m g ~ L}^{-1}\right)$ & 7,8 & ALD & $>93$ & 17,07 & $0,0017^{*}$ \\
\hline
\end{tabular}

Em que: $\mathrm{R}=$ Remoção; $\mathrm{t}$ = valor de $\mathrm{t}$ calculado pelo teste; $\mathrm{ALD}=$ abaixo do limite de detecção do equipamento; * = significativo a $5 \%$ de probabilidade de erro, pelo teste $t$.

A partir dos dados apresentados na Tabela 5 observou-se que para todos os parâmetros foram obtidas remoções significativas $(\mathrm{p}<0,05)$ pelo teste t de Student, o que demonstra a efetividade alcançada com o tratamento por filtração do efluente clarificado em carvão ativado granular para os parâmetros estudados.

Verificou-se que a utilização do ciclo completo foi eficaz, sendo possível obter remoções altamente satisfatórias (>90\%) para os parâmetros cor verdadeira, turbidez e principalmente para o fenol, o qual ficou abaixo do valor limite de detecção do equipamento empregado, no caso, de $0,5 \mathrm{mg} \mathrm{L}^{-1}$.

Além disso, observou-se aumento na remoção de DQO em relação aos tratamentos anteriormente estudados, tendo-se atingido percentual de 64\% de remoção de DQO. 
Fazendo um comparativo entre os tratamentos, a etapa I de coagulação/floculação e sedimentação foi essencial para a remoção de poluentes na fase particulada e coloidal, o que foi comprovado pelos elevados percentuais de remoção dos parâmetros turbidez e cor, mas não foi suficiente para remoção de matéria orgânica solúvel e fenol, parâmetros esses que só foram mais eficientemente removidos com o emprego da etapa III por ciclo completo com filtração em carvão ativado, fazendo crer que essa alternativa possa ser utilizada como pós-tratamento de efluentes de indústrias de papel e celulose no intuito de contribuir sobremaneira para obtenção de efluentes que possam ser lançados nos corpos d'água sem comprometimento da qualidade natural dos mananciais ou para utilização em diversas finalidades de reúso.

\section{Avaliação do perfil espectrofotométrico das amostras estudadas}

Na Figura 1 são apresentados os resultados da varredura espectrofotométrica realizada com a amostra: bruta, coagulada/floculada/sedimentada, e das amostras bruta e coagulada filtradas.

\section{Figura 1 - Perfil espectrofotométrico do efluente da indústria de papel e celulose e das} amostras tratadas por coagulação/floculação/sedimentação e filtração em CAG.

Figure 1 - The UV-vis spectrophotometric analysis of pulp and paper industry raw wastewater and samples treated by coagulation-flocculation-sedimentation and GAC filtration.

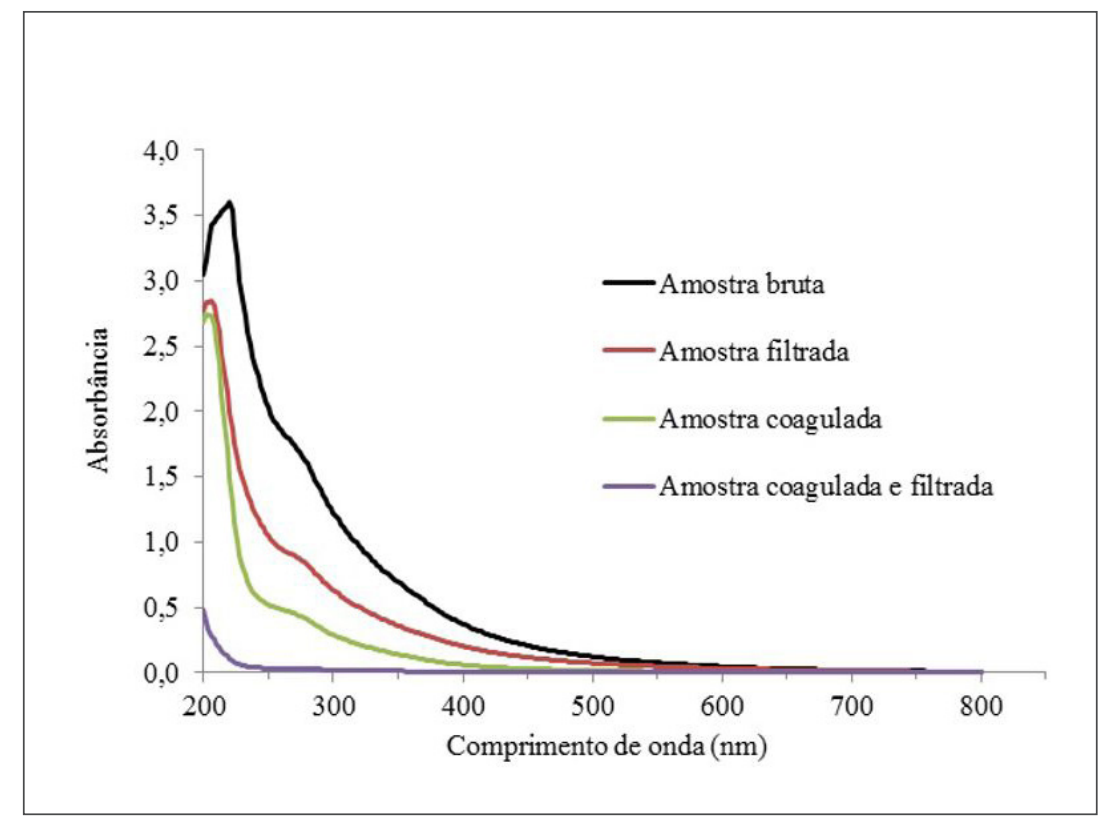

Fonte: Autores (2018)

A partir da análise da Figura 1 é possível destacar a presença de compostos lignínicos na amostra bruta, indicados pela área sobre o comprimento de onda em $280 \mathrm{~nm}$. Esse resultado condiz com as características do efluente da indústria de papel e celulose. Também é possível observar a redução na curva da amostra bruta em relação as amostras após os tratamentos, indicando a remoção desses compostos.

Além disso, com base nas informações obtidas com a varredura espectrofotométrica foi possível calcular as eficiências obtidas no tratamento quanto à redução da faixa espectral (200 $800 \mathrm{~nm}$ ), em que as remoções, em relação à amostra bruta, foram de $42 \%, 67 \%$ e $97 \%$ para a amostra filtrada, amostra coagulada e amostra coagulada e filtrada, respectivamente. 
Ainda, com a leitura da área espectral observou-se elevada redução na banda de absorção da região UV entre 200 e $350 \mathrm{~nm}$, a qual é associada à matéria orgânica, bem como na região do UV entre 350 e $700 \mathrm{~nm}$, a qual é relacionada à presença de cor. Com a varredura espectrofotométrica foi possível confirmar os valores de redução de DQO e cor obtidos a partir das análises específicas desses parâmetros.

Os resultados apresentados na Figura 1 condizem com os obtidos a partir das análises dos demais parâmetros estudados, em que a coagulação (Tabela 3) foi superior à filtração (Tabela 4) e que, esses tratamentos quando combinados (Tabela 5) permitiram o alcance de elevadas eficiências de tratamento, com reduções percentuais acima de $90 \%$, exceto para o parâmetro DQO, em que atingiram-se reduções máximas de 64\%.

\section{Conclusões}

A partir dos resultados obtidos na pesquisa, é possível concluir que:

A Série I da pesquisa, em que foi empregada a etapa de coagulação, apresentou boa resposta quando aplicada no tratamento do efluente de papel e celulose, com remoções de: $89 \%$, $62 \%$ e $60 \%$ para cor, turbidez e fenol, respectivamente;

$\mathrm{O}$ tratamento do efluente bruto unicamente a partir da filtração em CAG repercute em remoções intermediárias das cargas poluentes desse tipo de efluente industrial, com obtenção de reduções dos parâmetros estudados cor, turbidez e fenol, respectivamente de $45 \%, 62 \%$ e $47 \%$;

Com o tratamento por ciclo completo remoções acima de $90 \%$ foram alcançadas para os parâmetros estudados, com exceção da DQO (64\%). Com destaque para a redução de fenol que ficou abaixo dos níveis mínimos de $0,5 \mathrm{mg} \mathrm{L}^{-1}$ exigidos pela legislação ambiental em vigor;

A opção de pós-tratamento do efluente industrial de celulose e papel por ciclo completo: coagulação/floculação/sedimentação e filtração em carvão ativado é muito eficiente, podendo ser utilizada na remoção de cor e fenol de efluentes provenientes do processo Kraft.

\section{Agradecimentos}

À CAPES pela concessão de bolsa de estudos.

\section{Referências}

ASSOCIANÇÃO BRASILEIRA DE NORMAS TÉCNICAS. NBR 9898: Preservação e técnicas de amostragem de efluentes líquidos e corpos receptores. Rio de Janeiro, 1987.

AMERICAN PUBLIC HEALTH ASSOCIATION;AMERICANWATERWORKS ASSOCIATION; WATER ENVIRONMENT FEDERATION. Standart methods for examination of water and wastewater. $19^{\text {th }}$ ed. Washington: American Public Health Association, 2012.

BAETTKER, E. C. Avaliação do desempenho de filtros anaeróbios preenchidos com diferentes meios suportes no tratamento de água residuária sintética. 2015. Dissertação (Mestrado em Engenharia Civil) - Universidade Tecnológica Federal do Paraná, Curitiba, 2015.

BONFIM, L. T. et al. Análise da eficiência do conjunto coagulação/precipitação no pós-tratamento de efluente de uma indústria de papel e celulose. Revista de Engenharia e Tecnologia, Ponta Grossa, v. 5, n. 3, p. 15-24, 2012.

BRASIL. Ministério do Meio Ambiente. Conselho Nacional do Meio Ambiente. Resolução CONAMA $n^{\circ}$ 430/11, de 13 de maio de 2011. Disponível em: http://www.mma.gov. br. Acesso em: 26 jan. 2018.

COMPANHIA DE TECNOLOGIA DE SANEAMENTO AMBIENTAL (SP). Guia técnico ambiental da indústria de papel e celulose, Série P+L. São Paulo, 2008. 49 p. 
CLETO, E. P.; GUIMARÃES, L. G.; BUZZINI, A. P. A remoção de cor em efluente da indústria de papel e celulose por processo eletrolítico. São Carlos, [s. n.], 2007. Disponível em: http://www. bvsde.paho.org/bvsaidis/aresidua/mexico/01232p04.pdf. Acesso em: jan. 2018.

CUNHA, F. S.; AGUIAR, A. P. Métodos para remoção de derivados fenólicos de efluentes aquosos. Revista Virtual de Química, Rio de Janeiro, v. 6, n. 4, p. 844-865, mar. 2014.

DI BERNARDO, L.; DANTAS, A. D. B. Métodos e técnicas de tratamento de água. 2. ed. São Carlos: Rima, 2005. v. 1.

DI BERNARDO, L.; DANTAS, A. D. B.; VOLTAN, P. E. N. Tratabilidade de água e dos resíduos gerados em estações de tratamento de água. São Carlos: LDiBe, 2011. 454 p.

FOLLMANN, H. V. D. M. Avaliação da ultrafiltração e da adsorção em carvão ativado no tratamento avançado de efluente de uma indústria de papel e celulose. 2017. Dissertação (Mestrado em Ciências Florestais) - Universidade Estadual do Centro-Oeste, Irati, 2017.

INDÚSTRIA BRASILEIRA DE ÁRVORES. Relatório anual 2017. Brasília, 2017. 80 p. Disponível em: http://iba.org/images/shared/Biblioteca/IBA_RelatorioAnual2017.pdf. Acesso em: 26 jan. 2018.

KURITZA, J. C. Aplicação da coagulação, floculação, sedimentação como pós-tratamento de efluente de uma indústria de papel e celulose. 2012. Dissertação (Mestrado em Ciências Florestais) - Universidade Estadual do Centro-Oeste, Irati, 2012.

LACORTE, S. et al. Organic compounds in paper-mill process water and effluents. Trends in Analytical Chemistry, Amsterdam, v. 22, n. 10, 2003.

LIBÂNIO, M. Fundamentos de qualidade e tratamento de água. 3. ed. Campinas: Átomo, 2010.

MANCUSO, P. C. S.; SANTOS, H. F. Reuso de água. 1. ed. São Paulo: Manole, 2003.

METCALF, L.; EDDY, H. P. Tratamento de efluentes e recuperação de recursos. 5. ed. Brasil: McGraw Hill, 2016.

MIERZWA, J. C.; HESPANHOL, I. Água na Indústria - Uso Racional e Reúso. 1. ed. São Paulo: Oficina de Textos, 2005. p. 144.

MONTIBELLER, M. M. Remoção de fenol de águas residuárias utilizando método de polimerização e precipitação com enzima horseradish peroxidase (HRP). 2012. Dissertação (Mestrado em Engenharia Química) - Universidade Federal de Santa Catarina, Florianópolis, 2012.

PIVELI, R. P.; KATO, M. T. Qualidade das águas e poluição: aspectos físico-químicos. 1. ed. São Paulo: ABES, 2005.

SILVA FILHO, A. Tratamento terciário de efluente de uma indústria de refrigerantes visando ao reuso - um estudo de caso. Dissertação (Mestrado) - Universidade Federal do Rio de Janeiro - UFRJ, Escola de Química, 2009.

THOMPSON, G. et al. The treatment of pulp and paper mill effluent: a review. Bioresource Tecnology, [s. l.], v. 77, p. 275-286, 2001.

VACLAVIK, F. D. Avaliação e otimização do uso de zeólitas no tratamento terciário de efluentes líquidos industriais. 2010. Trabalho de Conclusão de Curso (Química Industrial) Universidade Federal do Rio Grande do Sul, Porto Alegre, 2010. 